\title{
Association between adiposity indicators and cardiorespiratory fitness among rural northeastern Thai adolescents
}

\author{
Weerachat Srichan, Tippawan Pongcharoen*, Kunchit Judprasong, Pattanee \\ Winichagoon, Sueppong Gowachirapant \& Wanphen Wimonpeerapattana
}

Institute of Nutrition, Mahidol University, Salaya, Phutthamonthon, Nakhon Pathom, Thailand

\begin{abstract}
Introduction: Obesity or high adiposity is known to be associated with various medical consequences, such as diabetes mellitus, hypertension, coronary heart disease and metabolic syndrome. High adiposity and poor cardiorespiratory fitness (CRF) have been found to be related with higher risks of developing cardiovascular disease (CVD). However, previous studies in Asia reported inconsistent findings on the association between obesity or high adiposity, based on various indicators, with impaired CRF. This study investigated the association between adiposity indicators and $\mathrm{CRF}$ in terms of maximal oxygen uptake $\left(\mathrm{VO}_{2}\right.$ max) in adolescents from rural northeastern Thailand. Methods: This study was performed among 486 adolescents aged 14-15 years old in Khon Kaen province, Thailand. Adiposity indicators included body mass index-for-age $z$-scores (BAZ), waist circumference (WC), waist-to-hip ratio (WHR), waist-to-height ratio (WHtR) and percent body fat $(\% \mathrm{BF})$ based on deuterium dilution technique. Results: Male adolescents had higher WHR and $\mathrm{VO}_{2}$ max than female adolescents, while female adolescents had higher \%BF and WHtR. Adolescents who had higher adiposity tended to have lower $\mathrm{VO}_{2}$ max, especially among females in which the lowest $\mathrm{VO}_{2}$ max was found in the highest quintile of adiposity indicators, including BAZ, WC, WHtR and \%BF. Conclusion: Adolescents with higher adiposity tended to have poorer CRF. Based on previous knowledge that both high adiposity and poor CRF may lead to higher risks of developing CVD, this suggests that obese adolescents should be considered and managed at an early age in order to maintain optimal CRF.
\end{abstract}

Keywords: Adiposity, cardiorespiratory fitness, adolescent

\section{INTRODOCTION}

Unhealthy eating habits, physical inactivity and sedentary lifestyle are regarded as important contributors to an increase in obesity prevalence. Obesity is known to be associated with various medical consequences, such as diabetes mellitus, hypertension, coronary heart disease and metabolic syndrome (Holvoet et al., 2004). Currently, the prevalence of cardiovascular disease (CVD) is increasing and it is the leading cause of mortality and morbidity worldwide. Cardiorespiratory fitness (CRF) and body composition have been found to be related with the risk of CVD, even among children and adolescents (Eisenmann et

\footnotetext{
*Corresponding author: Dr Tippawan Pongcharoen Institute of Nutrition, Mahidol University, Salaya, Phutthamonthon, Nakhon Pathom 73170 Thailand Tel: 6628002380 Ext 312; Fax: 662 4419344; E-mail: tippawan.pon@mahidol.ac.th https:/ / doi.org/ 10.31246/mjn-2019-0092
} 
al., 2007; Jago et al., 2010). Eisenmann et al. (2007) studied the relationship between CRF and fatness with CVD risk score among children and found that both high fatness or high adiposity and low fitness were related with higher CVD risk scores. Similarly, another study reported that both high fatness and low fitness increased cardiometabolic risk factors among children (Jago et al., 2010). Moreover, the relationship between high adiposity and low CRF has been reported in children and adolescents (Jambarsang, Dana \& Farzanegi, 2014; Watanabe, Nakadomo \& Maeda, 1994; Burns et al., 2013). In Western countries, percent body fat $(\% \mathrm{BF})$ was reported to be negatively associated with CRF (Burns et al., 2013; Ramirez-Velez et al., 2017). A study in the Middle Eastern country also reported similar findings - a negative association between body mass index (BMI) and $\mathrm{CRF}$, although $\mathrm{BF}$ was not assessed in this study (Jambarsang et al., 2014). However, findings were not consistently significant when BMI was used as an adiposity indicator (Burns et al., 2013; Ramirez-Velez et al., 2017; Mota et al., 2006). Inconsistent findings were also reported among Asian countries. Several studies reported a negative association between adiposity and CRF among children and adolescents based on either anthropometric or BF indicators (Watanabe et al., 1994; Gonzalea-Suarez et al., 2013; Kim et al., 2016).

Inconsistent findings might be due to the variations in adiposity indicators used among the studies. Adiposity indicators namely BMI, \%BF, waist circumference (WC) and hip circumference (HC), are accepted globally as indicators of nutritional status in children and adolescents (Chatterjee, Chatterjee \& Bandyopadhyay, 2006). It is known that at a certain $\mathrm{BMI}, \% \mathrm{BF}$ varies depending on age, sex and ethnic groups (WHO
Expert Consultation, 2004). Among the various anthropometric adiposity indicators, waist-to-hip-ratio (WHR), a marker of central adiposity, was found to be the best adiposity risk indicator for acute myocardial infarction in most populations worldwide (Yusuf et al., 2005). Waist-to-height-ratio (WHtR), which is another central adiposity indicator, has the advantage of not requiring an age and sex-specific reference table, contrary to WC (Burns et al., 2013). High WHtR has been shown to be related with a higher risk of CVD (Mokha, Srinivasan \& DasMahapatra, 2010; Hara et al., 2002).

The evidences above indicate that high adiposity and poor CRF are related with the risk of developing CVD, as high adiposity is related with poor fitness. Since abnormal CVD risks in children or adolescents with high adiposity may not be shown, evidence of a relationship between adiposity and CRF should be ascertained in these groups. The strength of evidence on the negative relationship between adiposity and CRF may help to advocate people in managing or preventing adiposity early in life in order to lessen the risks of CVD later. Although there is a well-known association between body composition and CRF in children and adults (Jambarsang et al., 2014; Watanabe et al., 1994; Burns et al., 2013), studies conducted in the Asian adolescent population are limited and those with the use of various indicators have reported inconsistent findings. Since different adiposity indicators may reflect adiposity differently depending on age, sex and ethnic groups, studies that could strengthen the evidence of a relationship between adiposity and CRF in Asian adolescents are needed.

Hence, this study was designed to evaluate adiposity based on BMI-forage $z$-scores (BAZ), WC, WHR, WHtR and $\% \mathrm{BF}$, with $\mathrm{CRF}$ in terms of maximal 
oxygen uptake $\left(\mathrm{VO}_{2}\right.$ max) among rural Thai adolescents. Correlations between adiposity indicators and $\mathrm{VO}_{2} \max$ were assessed. We hypothesised that negative relationships between adiposity indicators and CRF would be shown in the adolescent population.

\section{MATERIALS AND METHODS}

\section{Study population}

The study was performed among adolescents who previously participated in a randomised controlled trial for iron and/or zinc supplementation during infancy from 1998 to 1999 , in Khon Kaen province, northeastern region of Thailand (Wasantwisut et al., 2006). 486 adolescents (257 males and 229 females), aged between 14-15 years old voluntarily participated in this study. These adolescents did not have any health conditions, including respiratory tract diseases, physical disabilities, mental problems, or other diseases that affected the assessment of CRF. The required sample size was estimated based on the correlation coefficients $(r)$ of the relationships between \%BF and WHtR with CRF $(r=0.261$ and $r=0.241$, respectively) from a previous study (Burns et al., 2013). Sample size estimates of 185 and 218 adolescents were considered as adequate to detect the relationship of interest with a $95.0 \%$ power and 0.05 significance level. All procedures were approved by the Mahidol University Central Institutional Review Board (COA. No.2013/008.1501). Written informed consent and assent were obtained from the parents and adolescents prior to the study. The study was registered at ClinicalTrials. gov (NCT01979770).

\section{Anthropometric assessment}

Body weight was measured to the nearest $0.1 \mathrm{~kg}$ with a calibrated digital scale (Tanita, BC-541), while height was measured to the nearest $0.1 \mathrm{~cm}$ with a stadiometer. BMI $\left(\mathrm{kg} / \mathrm{m}^{2}\right)$ was calculated as weight in kilogramme $(\mathrm{kg})$ divided by height in metres squared $\left(\mathrm{m}^{2}\right)$. BAZ was calculated and classified based on the 2007 World Health Organization (WHO) growth reference for school-aged children and adolescents (De Onis et al., 2007). All adolescents were in light clothing and without shoes while taking these measurements. WC was taken at the midway between the lowest rib and the iliac crest (Callaway et al., 1988). $\mathrm{HC}$ was measured at the widest part of the buttock. All the data were taken in triplicates and the average measurement was used in data analysis. WHR was obtained by dividing WC with $\mathrm{HC}$ and WHtR was obtained by dividing WC with height.

\section{Body fat (BF) assessment}

BF was estimated from total body water (TBW) assessed by the deuterium dilution technique. A baseline urine sample was collected and the deuterated water containing approximately $0.05 \mathrm{~g} /$ $\mathrm{kg}$ body weight of 99.0 atom \% deuterium oxide was administered orally. Three post-dose samples were collected at 3-, 4- and 5-hour after the initial dose was given. All urine samples were analysed for deuterium enrichment using the Isotope Ratio Mass Spectrometry (Sercon Limited, Cheshire, United Kingdom). TBW content was derived using the plateau approach (IAEA, 2009). Fat-free mass (FFM) was calculated from TBW using the Lohman's age appropriate hydration constants. BF (kg) was obtained by subtracting FFM from total body weight and was presented as \%BF.

\section{Maximal oxygen uptake ( $\left.\mathrm{VO}_{2} \max \right)$ assessment}

$\mathrm{VO}_{2}$ max is considered to be the gold standard in determining CRF (Wilmore \& Costill, 2005; Chatterjee, Chatterjee \& Bandyopadhyay, 2005). Nevertheless, 
the use of direct methods to measure $\mathrm{VO}_{2}$ max is limited because of its exhausting and impractical protocols, and requirement of a well-equipped laboratory. However, an earlier study had established the use of Queen's college step test to predict $\mathrm{VO}_{2}$ max indirectly (Chatterjee, Chatterjee \& Bandyopadhyay, 2004).

The Queen's college step test is a physical fitness test that was conducted to measure CRF (McArdle et al., 1972). The step test performed by the individuals involved step up and step down on a bench with a standardised step height of 16.25 inches $(41.25 \mathrm{~cm})$. The rates (cadence) at 24 steps per minute for males and 22 steps for females were set by a metronome. The test began after a brief demonstration and practice period. Adolescents were instructed to perform the steps using a four-step cadence, "up-up-down-down" continuously for 3 min. They had to maintain their determined stepping rhythm during the test and stop immediately on completion of the test. After that, they were required to remain standing and a heart rate monitor was used (Polar FT4, Kempele, Finland) to measure their heart rates at the $20^{\text {th }}$ second post-test. $\mathrm{VO}_{2}$ max was calculated using the McArdle's equations (McArdle et al., 1972):

Male: $\mathrm{VO}_{2} \max (\mathrm{mL} / \mathrm{kg} / \mathrm{min})=$ $111.30-0.42 \mathrm{x}$ heart rate $(\mathrm{bpm})$

Female: $\mathrm{VO}_{2} \max (\mathrm{mL} / \mathrm{kg} / \mathrm{min})=$ $65.81-0.1847 \times$ heart rate $(\mathrm{bpm})$

Those who were fit would have a higher $\mathrm{VO}_{2} \max$ and would be able to perform exercises with higher intensity for a longer period of time than unfit subjects.

\section{Statistical analysis}

Data were checked for normality and descriptive statistics were presented accordingly. Comparisons between male and female adolescents were performed using the independent sample $t$-test or Mann-Whitney $U$ test. Spearman's correlation was used to determine the correlation between $\mathrm{VO}_{2}$ max and adiposity indicators. Adiposity indicators including BAZ, WC, WHR, WHtR and \%BF were categorised into quintiles. One-way analysis of variance (ANOVA) was used to test the differences of $\mathrm{VO}_{2}$ max among quintiles of adiposity indicators and for linear trends across quintiles. All statistical analyses were performed using SPSS for Windows, version 19.0 (IBM Corp., Armonk, NY, USA). A $p$-value of $<0.05$ was considered statistically significant.

\section{RESULTS}

Characteristics of participating adolescents are presented in Table 1 . Male adolescents have higher WHR and $\mathrm{VO}_{2}$ max than female adolescents $(0.78$ vs. 0.76 and $49.6 \mathrm{~mL} / \mathrm{kg} / \mathrm{min}$ vs. $35.2 \mathrm{~mL} / \mathrm{kg} / \mathrm{min}$, respectively). BMI, HC, WHtR and \%BF were higher in females than males $\left(19.0 \mathrm{~kg} / \mathrm{m}^{2}\right.$ vs. $18.5 \mathrm{~kg} /$ $\mathrm{m}^{2}, 86.3 \mathrm{~cm}$ vs. $84.0 \mathrm{~cm}$ and $26.6 \%$ vs. $15.8 \%$, respectively), while $\mathrm{BAZ}$ and $\mathrm{WC}$ were not significantly different in both genders.

Table 2 shows the correlation between $\mathrm{VO}_{2}$ max and adiposity indicators (BAZ, WC, WHR, WHtR and \%BF). $\mathrm{VO}_{2}$ max had a significant, negative correlation with $\% \mathrm{BF}$ in both male and female adolescents $(r=-0.17, p=0.009$ and $r=-0.38, p=0.000$, respectively). In female adolescents, $\mathrm{VO}_{2}$ max was also significantly negatively correlated with BAZ, WC, WHR and WHtR $(r=-0.24, \quad p=0.000, \quad r=-0.24, \quad p=0.000$, $r=-0.14, p=0.040$ and $r=-0.23, p=0.000$, respectively). For illustrative purposes, the negative relationships between \%BF and $\mathrm{VO}_{2}$ max among males and females are shown in Figure 1.

Mean $\mathrm{VO}_{2}$ max by quintiles of adiposity indicators in males and females are presented in Table 3. Among males, there were no differences in $\mathrm{VO}_{2}$ max by 


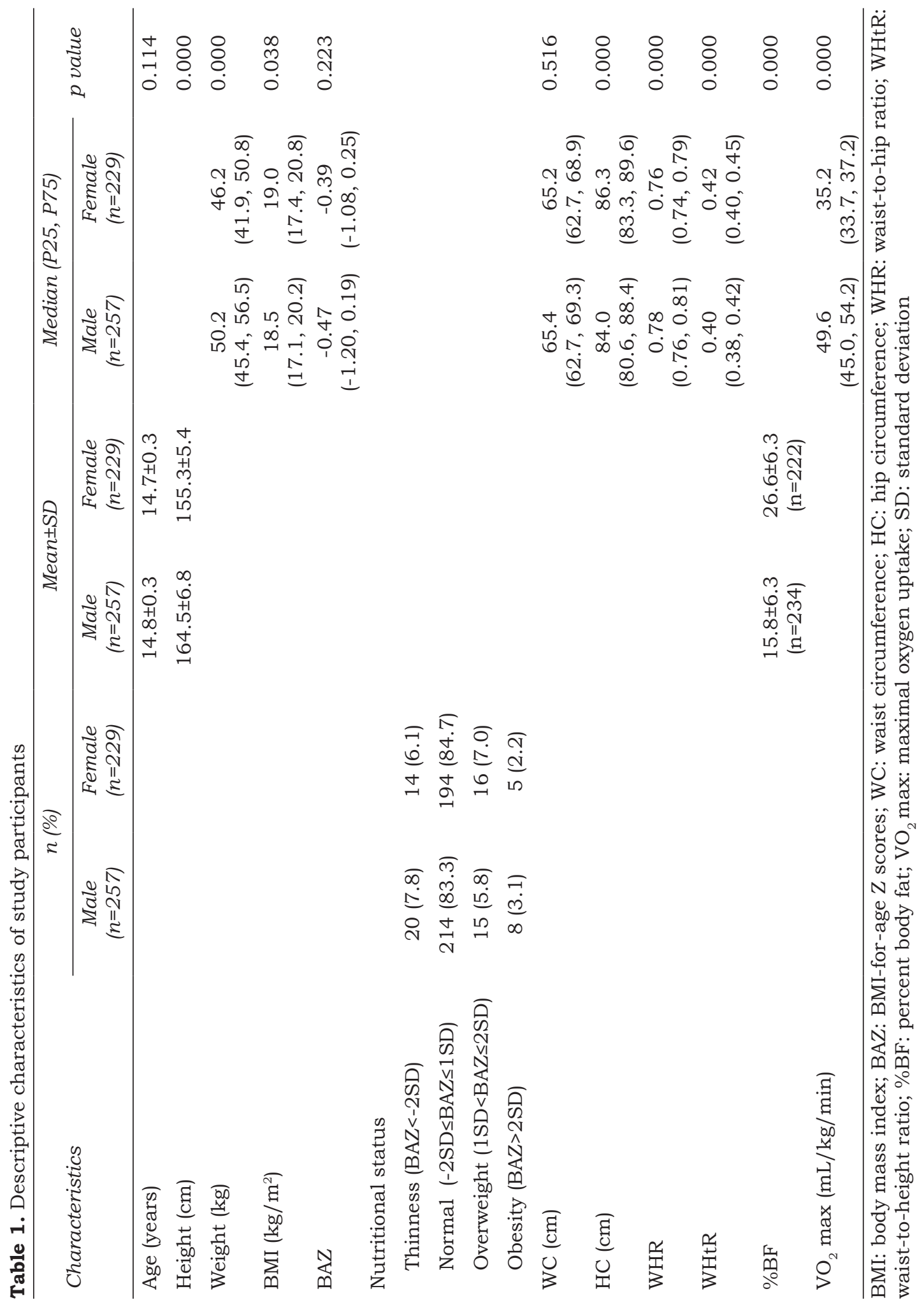


Table 2. Correlation coefficients $(r)$ between $\mathrm{VO}_{2} \max (\mathrm{mL} / \mathrm{kg} / \mathrm{min})$ and adiposity indicators

\begin{tabular}{lccc}
\hline Adiposity indicator & $r$ & $p$-value & $n$ \\
\hline Male & & & 257 \\
BAZ & -0.07 & 0.274 & 257 \\
WC (cm) & -0.02 & 0.760 & 257 \\
WHR & 0.01 & 0.851 & 257 \\
WHtR & -0.04 & 0.499 & 234 \\
\%BF & -0.17 & 0.009 & \\
Female & & & 229 \\
BAZ & -0.24 & 0.000 & 229 \\
WC (cm) & -0.24 & 0.000 & 229 \\
WHR & -0.14 & 0.040 & 229 \\
WHtR & -0.23 & 0.000 & 222 \\
\%BF & -0.38 & 0.000 & . \\
\hline
\end{tabular}

BAZ: BMI-for-age z-scores; WC: waist circumference; WHR: waist-to-hip ratio; WHtR: waistto-height ratio; \%BF: percent body fat

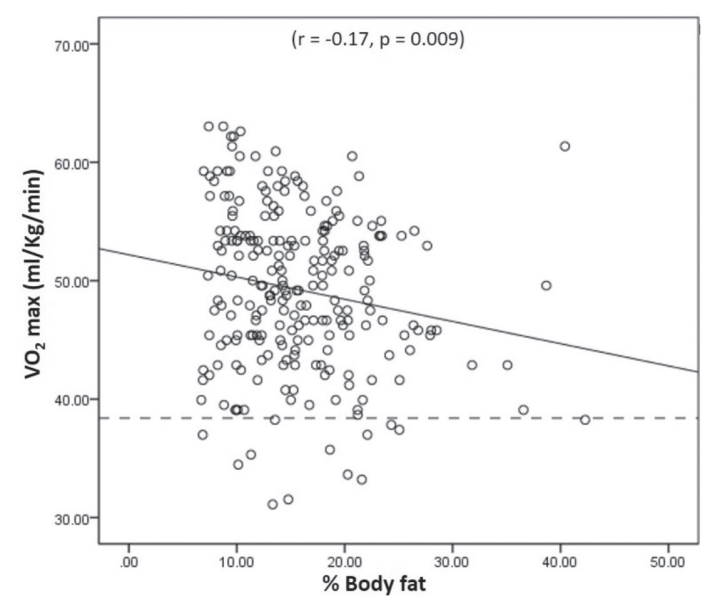

(A) Male

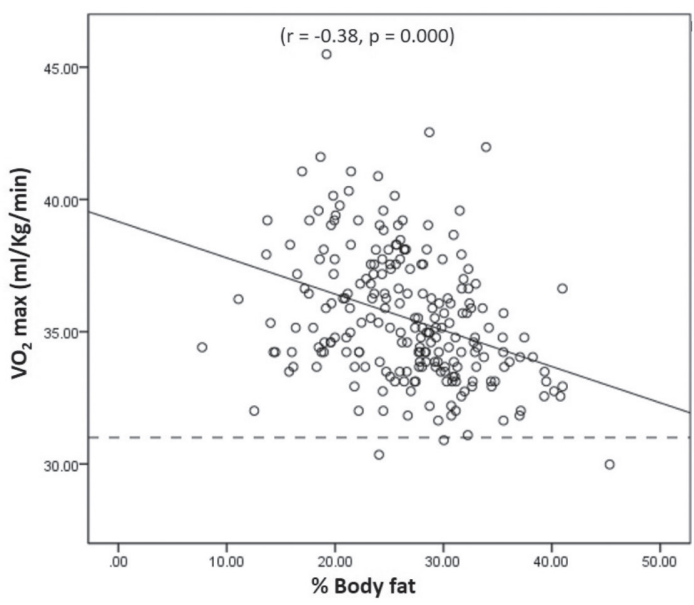

(B) Female

Figure 1. Negative relationship between $\% \mathrm{BF}$ and $\mathrm{VO}_{2} \max (\mathrm{mL} / \mathrm{kg} / \mathrm{min})$ in male $(\mathrm{A})$ and female (B) adolescents

quintiles of BAZ, WC, WHR and WHtR. However, there was a significant trend of decreasing $\mathrm{VO}_{2}$ max with increasing $\% \mathrm{BF}$ quintiles ( $p$ for trend $<0.05$ ). Among females, $\mathrm{VO}_{2}$ max significantly declined with increasing quintiles of $\mathrm{BAZ}, \mathrm{WC}$, WHtR and \%BF ( $p$ for trend <0.05). However, this relationship did not show significance for the quintiles of WHR.

\section{DISCUSSION}

Overall, this study showed that adolescents who had higher adiposity indicators tended to have lower CRF, especially among females. However, this relationship was not consistent among all adiposity indicators in male adolescents. Nonetheless, male 
Table 3. $\mathrm{VO}_{2} \max (\mathrm{mL} / \mathrm{kg} / \mathrm{min})^{\dagger}$ by quintiles of adiposity indicators

\begin{tabular}{lcccccc}
\hline \multirow{2}{*}{ Adiposity indicator } & \multicolumn{7}{c}{ Mean \pm SD } \\
\cline { 2 - 6 } & $Q 1$ & $Q 2$ & $Q 3$ & $Q 4$ & Q5 & -trend \\
\hline Male & & & & & & \\
$\mathrm{VO}_{2}$ max by BAZ quintiles & $49.4 \pm 6.1$ & $49.6 \pm 7.6$ & $49.7 \pm 7.5$ & $50.9 \pm 5.6$ & $47.5 \pm 6.4$ & 0.421 \\
$\mathrm{VO}_{2}$ max by WC quintiles & $48.9 \pm 5.4$ & $49.4 \pm 8.0$ & $49.9 \pm 7.2$ & $50.7 \pm 5.9$ & $48.1 \pm 6.7$ & 0.950 \\
$\mathrm{VO}_{2}$ max by WHR quintiles & $50.2 \pm 7.1$ & $47.4 \pm 6.7$ & $49.5 \pm 6.5$ & $50.8 \pm 6.6$ & $49.1 \pm 6.4$ & 0.681 \\
$\mathrm{VO}_{2}$ max by WHtR quintiles & $50.3 \pm 6.7$ & $48.6 \pm 7.7$ & $48.7 \pm 6.3$ & $51.0 \pm 5.9$ & $48.5 \pm 6.7$ & 0.691 \\
$\mathrm{VO}_{2}$ max by \%BF quintiles & $51.2 \pm 7.5$ & $49.5 \pm 7.0$ & $49.4 \pm 6.4$ & $48.8 \pm 5.6$ & $47.2 \pm 6.8$ & 0.006 \\
$\mathrm{Female}$ & & & & & & \\
$\mathrm{VO}_{2}$ max by BAZ quintiles & $36.1 \pm 2.5$ & $36.0 \pm 2.8$ & $35.8 \pm 3.0$ & $35.8 \pm 2.1$ & $34.2 \pm 2.1$ & 0.001 \\
$\mathrm{VO}_{2}$ max by WC quintiles & $35.9 \pm 2.5$ & $35.9 \pm 2.3$ & $36.7 \pm 3.3$ & $35.3 \pm 2.1$ & $34.2 \pm 2.2$ & 0.001 \\
$\mathrm{VO}_{2}$ max by WHR quintiles & $35.5 \pm 2.1$ & $36.2 \pm 2.9$ & $36.1 \pm 3.0$ & $35.5 \pm 2.2$ & $34.7 \pm 2.5$ & 0.055 \\
$\mathrm{VO}_{2}$ max by WHtR quintiles & $35.8 \pm 2.3$ & $36.1 \pm 2.9$ & $36.0 \pm 2.2$ & $35.9 \pm 2.9$ & $34.1 \pm 2.1$ & 0.002 \\
$\mathrm{VO}_{2}$ max by \%BF quintiles & $36.7 \pm 2.7$ & $36.2 \pm 2.5$ & $35.6 \pm 2.1$ & $34.8 \pm 2.3$ & $34.3 \pm 2.1$ & 0.000 \\
\hline
\end{tabular}

$\mathrm{VO}_{2}$ max: maximal oxygen uptake; BAZ: BMI-for-age $z$-scores; WC: waist circumference; WHR: waist-to-hip ratio; WHtR: waist-to-height ratio; \%BF: percent body fat; SD: standard deviation

adolescents who had higher \%BF tended to have lower CRF. Our findings were not entirely in agreement with previous studies conducted in Asia (Watanabe et al., 1994; Gonzalez-Suarez et al., 2013; Kim et al., 2016). Similar negative associations of adiposity and CRF in both males and females were reported earlier in a study among Japanese children and adolescents, when adiposity was assessed as \%BF and CRF was assessed as $\mathrm{VO}_{2}$ max (Watanabe et al., 1994). However, the sample size in that study was quite small $(N=37)$ and it might be due to the limitation of the underwater weighing technique used for body composition assessment. In comparison with a study in the Philippines (GonzalezSuarez et al., 2013), our study population was older and had lower proportion of overweight and obesity. Hence, this may explain the discrepancy between our findings and that of theirs. We reported significantly negative associations of BAZ, WC, WHR and WHtR with CRF only in female adolescents, while they reported significantly negative associations between BMI and WC with CRF in both sexes. A study by Kim et al. (2016) in South Korea included both boys and girls aged 9-10 years old, as well as boys of older age (12-13 years old) only. As the proportion of overweight and obesity was quite high compared to our study $(28.0 \%$ vs. $8.9 \%)$, this might explain the significant, negative associations between anthropometric adiposity indicators with CRF reported in their study, while there were no such significant associations among males in our study.

A study conducted among US children also found that BMI, WC and WHtR were not associated with CRF, while \%BF was significantly associated with CRF (Burns et al., 2013). BF might be more appropriate to reflect adiposity among male adolescents compared with adiposity indicators developed from anthropometric measures such as BMI, WC, WHR or WHtR. A longitudinal study among healthy Caucasian 
children indicated the differences in the contribution of BF and FFM to BMI increase in male and female adolescents when they reached 13 years old of age (Maynard et al., 2001; Kirchengast, 2010). Although BMI increased in both sexes as age increased, however, the major contribution to BMI increase was total BF among females, while FFM among males. This may imply that high BMI or high levels of other anthropometric adiposity indicators may not be related with high $\mathrm{BF}$ in male adolescents, thus consequently resulting in no associations between anthropometric adiposity indicators and CRF.

The strengths of this study were that we used multiple indicators of adiposity. In this study, BF was assessed using the deuterium dilution technique. Although many methods exist to measure $\mathrm{BF}$, some methods may be expensive, expertise and appropriate equationrequired, or not field applicable (IAEA, 2009). The deuterium dilution technique is an accurate and suitable method for population-based studies. The use of $\mathrm{BF}$ as an adiposity indicator provided more reliable and consistent evidence on the relationship between adiposity and $\mathrm{CRF}$ compared with other proxy adiposity indicators developed from anthropometric measures.

We used $\mathrm{VO}_{2}$ max to reflect CRF. CRF can be assessed by various ergometer exercise techniques such as walking on treadmill, cycling, swimming and bench stepping. In this study, CRF was estimated using the Queen's college step test because it is one of the common physical fitness tests feasible for field application. This technique is usually performed at a fixed rhythm on a bench having a fixed height (McArdle et al., 1972). A previous study suggested that local muscular fatigue may occur before a true assessment of aerobic capacity if a step is too high. Consequently, the test may be more of a measurement of muscular endurance of the legs than of aerobic capacity (Shamsi et al., 2011). Thus, the height of the step bench should be adjusted to the participant's stature and this may decrease the interindividual variability in oxygen cost and heart rate during a task and, as such, may produce a valid prediction of $\mathrm{VO}_{2}$ max (Shamsi et al., 2011; Shahnawaz, 1978). However, a study that assessed aerobic capacity based on a fixed height and adjusted height of the bench $\left(90^{\circ}\right.$ knee joint angle) confirmed no significant difference in the aerobic capacity between these two levels of bench height (Ashley, Smith \& Reneau, 1997).

In addition to the height of the bench, accuracy of the heart rate should be considered when measuring $\mathrm{VO}_{2}$ max. Pulse rate counting might lead to an underestimation of post-exercise heart rate (John, Sforzo \& Swenson, 2007). Hence, we used an automatic heart rate monitor, which administration was simple and accurate.

This study had some limitations in which only young adolescents with a narrow age range (14-15 years old) were included and the prevalence of obesity was rather low (male $=3.1 \%$ and female $=2.2 \%$ ) among the study population. These limitations may restrict the generalisation of the findings.

\section{CONCLUSION}

Adolescents with higher adiposity tended to have lower CRF in this study. Especially among female adolescents, the highest quintile of adiposity indicators, e.g. \%BF and $\mathrm{BAZ}$ resulted in the lowest $\mathrm{VO}_{2}$ max. This may suggest that adolescents who have higher \%BF have lesser physical fitness and therefore, cannot perform well in physical activities, especially in a CRF task. In order to maintain optimal $\mathrm{CRF}$, which may consequently lessen the risk of CVD, obesity in individuals should be considered and managed at 
an early age. Future research is needed to develop suggested cut-off points for adiposity indicators that may contribute to low levels of $\mathrm{VO}_{2}$ max and to assess the extent to which high adiposity and low level of $\mathrm{VO}_{2}$ max during adolescence contribute to the higher risks of developing CVD later in life.

\section{Acknowledgements}

This project was financially supported by Mahidol University research grant and the joint grant awarded by the Office of Higher Education Commission and Mahidol University under the National Research Universities Initiative. The authors are grateful to the subjects and their parents for their participation in this study. We thank our colleagues at the Institute of Nutrition, Mahidol University and field staffs at Khon Kaen province for helping us with data collection. We also thank Christine Stanly for assistance in editing the manuscript.

\section{Authors' contributions}

WS, designed the study, collected data, contributed to statistical analysis, drafted the manuscript; TP, designed the study, collected data, drafted the manuscript; KJ, designed and supervised total body water sample analysis; PW, designed the study, critically revised the manuscript; SG, collected data, contributed to statistical analysis, drafted the manuscript; WW, contributed to statistical analysis; all authors read and gave final approval of the manuscript.

\section{Conflict of interest}

The authors have no conflict of interest to declare.

\section{References}

Ashley CD, Smith JF \& Reneau PD (1997). A modified step test based on a function of subjects' stature. Percept Motor Skills 85:987993.

Burns R, Hannon JC, Brusseau TA, Shultz B \& Eisenman P (2013). Indices of abdominal adiposity and cardiorespiratory fitness test performance in middle-school students. $J$ Obes 2013:912460. http://dx.doi. org/10.1155/2013/912460

Callaway WC, Chumlea WC, Bouchard C, Himes $\mathrm{JH}$, Lohman TG, Martin AD, Mitchell CD, Mueller WH, Roche AF \& Seefeldt VD (1988). Circumferences. In TG Lohman, AF Rochd, R Martorell (eds) Anthropometric Standardization Reference Manual (pp. 39-54). Human Kinetics, Champaign, IL.
Chatterjee S, Chatterjee P \& Bandopadhyay A (2004). Validity of Queen's College step test for use with young Indian men. Br J Sports Med 38:289-291. doi: 10.1136/bjsm.2002.002212

Chatterjee S, Chatterjee P \& Bandyopadhyay A (2005). Validity of Queen's College step test for estimation of maximal oxygen uptake in female students. Indian J Med Res 121:32-35.

Chatterjee S, Chatterjee P \& Bandyopadhyay A (2006). Skinfold thickness, body fat percentage and body mass index in obese and non-obese Indian boys. Asia Pac J Clin Nutr 15(2):231235.

De Onis M, Onyango AW, Borghi E, Siyam A, Nishida C \& Siekmann J (2007). Development of a WHO growth reference for school-aged-children and adolescents. Bull World Health Organ 85:660667. doi: 10.2471/BLT.07.043497

Eisenmann JC, Welk GJ, Ihmels M \& Dollman J (2007). Fatness, fitness, and cardiovascular disease risk factors in children and adolescents. Med Sci Sports Exerc 39(8):1251-1256. doi: 10.1249/MSS.0b013e318064c8b0

Gonzalez-Suarez CB, Caralipio N, Gambito E, Reyes JJ, Espino RV \& Macatangay R (2013). The association of physical fitness with body mass Index and waist circumference in Filipino preadolescents. Asia Pac $J$ Public Health 25(1):74-83. doi: 10.1177/1010539511412764

Hara M, Saitou E, Iwata F, Okada T \& Harada $\mathrm{K}$ (2002). Waist-to-height ratio is the best predictor of cardiovascular disease risk factors in Japanese schoolchildren. $J$ Atheroscler Thromb 9:127-132.

Holvoet P, Kritchevsky SB, Tracy RP, Mertens A, Rubin SM, Butler J, Goodpaster B \& Harris TB (2004). The metabolic syndrome, circulating oxidized LDL, and risk of myocardial infraction in well-functioning elderly people in the health, aging, and body composition cohort. Diabetes 53:396-400.

IAEA (2009). Assessment of body composition and total energy expenditure in humans using stable isotope techniques: IAEA Human Health Series. No. 3. International Atomic Energy Agency, Vienna. From http://www.iaea.org/ books.

Jago R, Drews KL, McMurray RG, Thompson D, Volpe SL, Moe EL, Jakicic JM, Pham TH, Bruecker S, Blackshear TB \& Yin Z (2010). Fitness, fitness, and cardiometabolic risk factors among sixth-grade youth. Med Sci Sports Exerc 42(8):1502-1510. doi: 10.1249/ MSS.0b013e3181d322c4 
Jambarsang V, Dana A \& Farzanegi P (2014). Prevalence of obesity and its relationship with cardiorespiratory fitness in adolescent students of Babol city. Res J Sport Sci 2(2):32-37.

John D, Sforzo GA \& Swenson T (2007). Monitoring exercise heart rate using manual palpation. ACSMs Health Fit $J$ 11(6):1-4.

Kim HJ, Lee KJ, Jeon YJ, Ahn MB, Jung IA, Kim $\mathrm{SH}$, Cho WK, Cho KS, Park SH, Jung MH, Lee JH \& Suh BK (2016). Relationships of physical fitness and obesity with metabolic risk factors in children and adolescents: Chungju city cohort study. Ann Pediatr Endocrinol Metab 21:31-38. http://dx.doi.org/10.6065/ apem.2016.21.1.31

Kirchengast S (2010). Gender differences in body composition from childhood to old age: an evolutionary point of view. J Life Sci 2(1):1-10.

Maynard LM, Wisemandle W, Roche AF, Chumlea WC, Guo SS \& Siervogel RM (2001). Childhood body composition in relation to body mass index. Pediatrics 107:344-350.

McArdle WD, Katch FI, Pechar GS, Jacobson L \& Ruck S (1972). Reliability and interrelationships between maximal oxygen intake, physical work capacity and step test scores in college woman. Med Sci Sports Exerc 4:182-186.

Mokha JS, Srinivasan SR \& DasMahapatra P (2010). Utility of waist-to-height ratio in assessing the status of central obesity and related cardiometabolic risk profile among normal weight and overweight/obese children: The Bogalusa Heart Study. BMC Pediatrics 10(3):73. http://www.biomedcentral. com/1471-2431/10/73

Mota J, Flores L, Flores L, Ribeiro JC \& Santos MP (2006). Relationship of single measures of cardiorespiratory fitness and obesity in young schoolchildren. Am J Hum Biol 18:335-341. doi: 10.1002/ajhb.20513

Ramirez-Velez R, Correa-Bautista JE, RamosSepulveda JA, Pineros-Alvarez CA, Giraldo LI, Izquierdo M, Garcia-Hermoso A, RodriquezRodriguez F \& Cristi-Montero C (2017). Aerobic capacity and future cardiovascular risk in Indian community from a low income area in Cauca, Colombia. Ital J Pediatr 43(1):28. doi: 10.1186/s 13052-017-0347-y
Shahnawaz H (1978). Influence of limb length on a stepping exercise. J Appl Physiol 44(3):346349.

Shamsi MM, Ghaderi M, Alinejed HA \& Gharakhanlou R (2011). Maximal step test: a new approach to step test improvements. World Appl Sci J 12(11):2058-2060.

Wasantwisut E, Winichagoon P, Chitchumroonchokchai C, Yamborisut $\mathrm{U}$, Boonpraderm A, Pongcharoen T, Sranacharoenpong K \& Russameesopaphorn W (2006). Iron and zinc supplementation improved iron and zinc status, but not physical growth, of apparently health, breast-fed infants in rural communities of northeast Thailand. $J$ Nutr 136(9):2405-2411.

Watanabe K, Nakadomo F \& Maeda K (1994). Relationship between body composition and cardiorespiratory fitness in Japanese junior high school boys and girls. Ann Physiol Anthropol 13(4):167-174.

WHO Expert Consultation (2004). Appropriate body-mass index for Asian populations and its implications for policy and intervention strategies. Lancet 363(9403): 157-63.

Wilmore JH \& Costill DL (2005). Physiology of Sport and Exercise (3rd Ed). Human Kinetics, Champaign, IL.

Yusuf S, Hawken S, Ounpuu S, Bautista L, Franzosi MG, Commerford P, Lang CC, Rumboldt Z, Onen CL, Lisheng L, Tanomsup S, Wangai P, Razak F, Sharma AM \& Anand SS (2005). Obesity and the risk of myocardial infraction in 27000 participants from 52 countries: a casecontrol study. Lancet 366:1640-1649. 